\title{
Exploring the user experience through collage
}

\author{
Dana McKay \\ Dept. of Computer Science \\ University of Waikato \\ Hamilton, New Zealand \\ dana@cs.waikato.ac.nz
}

\author{
Sally Jo Cunningham \\ Dept. of Computer Science \\ University of Waikato \\ Hamilton, New Zealand \\ sallyjo@cs.waikato.ac.nz
}

\author{
Kirsten Thomson \\ Dept. of Computer Science \\ University of Waikato \\ Hamilton, New Zealand \\ kthomson@cs.waikato.ac.nz
}

\begin{abstract}
We explore the use of collage in requirements elicitation, as a tool to support potential end-users in expressing their impressions, understanding, and emotions regarding a system.
\end{abstract}

\section{Author Keywords \\ Requirements elicitation, thematic analysis, phenomenology, cultural probes, experience-centered design.}

\section{ACM Classification Keywords}

H5.m. Information interfaces and presentation (e.g., HCI): Miscellaneous.

\section{INTRODUCTION}

User studies are currently designed to access what people say (through interviews, focus groups, and surveys) and what people do (through observation of behavior both in lab-based studies and 'in the wild', in the participant's normal environment). New techniques attempt to engage the participant more directly, by asking the participant to create an artifact of some sort-a story, a photo, a collage, a drawing. The act of creation can allow the participant to express feelings, thoughts, and emotions that might otherwise have been inaccessible to a researcher [10].

In this paper, we explore the use of collage to elicit user experiences, to inform system design or re-design. Why collage? Collage is an attractive choice for a construction technique because it supports creative expression, but does not requiring participants to have prior artistic or technical skills. Nearly everyone has created a collage as a child; it is a common (and enjoyable) art project in kindergarten and primary school. It is possible to create attractive and meaningful collages with a minimum of time, effort, and skill-although if the participant does have an artistic flair or talent in sketching or even doodling, then the artifact created can be more deeply personalized and meaningful. While everyone is creative, to a greater or lesser extent [2], many people do not believe themselves to be creative and do not often express their innate creativity [12]. Because collage creation is a familiar activity and the result is based on re-using existing images, participants may find creating a collage less daunting than developing an artifact from scratch. Most of us are diffident about showing off the products of our creative efforts; since the elements of a collage are mainly selected rather than created by the collage developer, it may be easier to engage a participant in discussing a collage than, for example, a drawing.

This paper is organized as follows: we give an overview user study techniques in which participants engage in creative activities; we describe an experiment in which high school students participate in collage and focus groups to describe their mobile phone use; the resulting collages are analyzed, as a case study of methods of analysis suitable for collage data; and we discuss lessons learned about how to use collage more effectively in a user study.

\section{PREVIOUS WORK}

A number of new techniques to elicit user experiences and impressions have focused on involving the participant in situated, creative activities that culminate in the construction of an artifact. The artifact then can serve as the basis for further study, conversation, and evaluation-as well as documenting the participant's view of the system under study.

Artifacts can be textual or verbal. Diary studies, in which participants are encouraged to create textual records of their thoughts, emotions, or activities, can capture the participant's perceptions of the context of the study. The acting writing can encourage reflection and heighten the participant's sensitivity to the experiences under study [11]. Narrative descriptions of experiences-in essence, storytelling - can convey the participant's sense of identity, personal tastes, and emotional references [1].

Cultural Probes [4] give participants a variety of ways to document, comment upon, or describe their thoughts and action. A cultural probe 'kit' might include a camera and a photo album for organizing the pictures, a map with stickers and markers to annotate it, or mobile camera phones to record activities through text (SMS) and multimedia

(MMS) messages. The kit would be accompanied by a set of activities to be accomplished or questions to be answered. Some may be straightforward, putting the participant in the role of observer of his/her own activities: for example, asking for a photo of the participant's home. Other activities may be, in the words of Gaver et al [4], 'more surreal tasks' intended to encourage creative and lateral thinking: for example, asking residents of a small Italian village to indicate on a village map the local equivalents of New York scenes such as the Statue of Liberty. 
Mobile probes [5] similarly ask participants to record, document, and create, with the emphasis on having this documentation occur during the activity under study. One challenge with this type of study is to create probe tasks such that the process of documentation (taking digital pictures, using a mobile phone) does not interfere with the activity. This constraint obviously limits the physical characteristics of the documentation-the participant cannot easily do more than snap a photo and make a brief oral or text commentary.

Collage has been put forward as an interface that can support user creativity and allow users to tailor the visual elements of their virtual environment. The CollageMachine [7] streams an interactive collage of web images, with the display and choice of images learned from preferences indicated by the user. The user thus becomes a part of the interface design. A Collaborage [9], or collaboratively constructed collage, has been used to support awareness of the presence and activities of group members.

A handful of user studies and product design studies have incorporated collage. In [5], for example, participants developed individual collage representations of the images they snapped in a mobile probes exercise. The individual collages were then discussed in small groups, to pull together the common themes from these individual experiences. The claim is that creating a visual representation such as a collage taps into emotional, abstract, sensitive, and experiential associations that participants may find difficult to otherwise express [10 -13]. Certainly the visual nature of a collage may be particularly appropriate for participants who find it tedious, timeconsuming, or potentially embarrassing to express their thoughts in words (a common difficulty with diary studies) [13].

\section{EXPERIMENTAL DESIGN}

Our focus for this research was on the use of collage in user studies. To allow us to compare the user insights gained through use of collage with the insights from more conventional user studies, we employed a 3-way experimental design: (a) focus group only, (b) collage only, and (c) collage-then-focus group. Our research participants were 12 year 10 (high school, aged 14 to 15) students, enrolled in an IT course. The students were separated into three groups of 4 . Each group participated in the three design factors, and the ordering of the conditions was different for each of the three groups. Each session was conducted over a 50 minute period.

Our general topic for exploration was 'how the participants use mobile phones'. We focussed on three social phenomena: (i) talking, (ii) texting, and (iii) photo taking and sharing (hereafter referred to as 'pxting'). Each group worked through each topic once, so that, for example, Group A used collage-only for 'talking', collage-then-focusgroup for 'texting', and focus-grou-only for 'photo taking'.
Focus group sessions: We had a pre-defined set of questions to ask during the focus group sessions. In most cases we stayed on-topic, only briefly exploring side issues or comments as they emerged. Participants were invited to sit in a semi-circle, facing the facilitator. Focus group sessions were video-recorded.

Collage only: We provided the participants with a list of topic areas, from which they could choose one to articulate through collage. The participants were not expected to discuss their finished collage or thoughts or processes once the session was concluded.

Collage, then focus group: We provided the participants with a list of topic areas, from which they could choose one or more as a subject for their collage. After 35 minutes the participants were requested to freely narrate the concepts within their collage through a focus group-style discussion. The discussion sessions were audio-recorded.

In this research we used collage as a tool to help participants (i) externalise and reflect on their experiences or desires and (ii) in the case of the collage-then-focus group session to develop an open environment for discussion and sharing.

Collage materials consisted of magazines, newspapers, different coloured pens, different coloured blank paper, yarn, and material shapes (e.g., flowers). Participants could stick, with glue or cellotape, these onto a canvas of white A3-size paper. Participants could choose their own materials.

Students were given debriefing questionnaires after all three tasks were completed. These questionnaires asked them to reflect on their confidence and degree of comfort with each experimental condition.

\section{ANALYSIS}

The collages were analysed using a grounded theory approach [6] from a phenomenological perspective [3]. Two analyses performed on the collages: a thematic analysis, and a content analysis.

This approach was taken to form a picture of what kinds of materials and images the students used to represent their ideas (the thematic analysis), and what kinds of ideas they represented with those materials (the content analysis). It also allowed us to assess how useful collage is as a tool for researchers, based on how much information we were able to glean from the collages.

The analysis of the collages was conducted in three stages:

1. The collages were examined briefly to see which categories for theme and content were immediately obvious

2. The collages were tagged with relevant content categories

3. The collages were tagged with relevant thematic categories. 
During the tagging, relevant thematic and content categories were added to the analysis as needed. Some of the categories are overlapping (notably any pictures they drew) so some aspects of the collage may have fallen into more than one theme or content category.

At the end of the analysis 20 content categories had emerged, including one to indicate that the participant chose to draw rather than collage, and an 'other' category which was used in 10 of 39 categories for items only seen once (see Table 1). Twelve thematic categories were elicited, with a thirteenth to denote collages where no obvious theme was visible (see Table 2).

\begin{tabular}{|ll|}
\hline Written text & Mobile phone pictures \\
Cut out text & Mobile phone advertisements \\
Cut out words and phrases & Landscapes or buildings \\
Drawn pictures & Cars \\
Drawn images only & Clothing \\
People & Other technology than mobile \\
& phones \\
Celebrities & Graphics and cartoons \\
Animals & 3D elements such as wool or \\
& ribbons glued on \\
Collaged-together pictures & Cut out paper \\
Humour & Other \\
\hline
\end{tabular}

\section{Table 1: Content categories}

Very few content categories allowed facets of the collages to fall into more than one category; notable examples were drawing (a drawing of a mobile phone would be included in both drawn image and mobile phones) and the collage category, in which the parts of the collage were also categorized). Mobile phone advertisements were a distinct category from mobile phone pictures. Advertisements were classified based on either obvious branding or repetition of an image in many collages.

Collages ranged from the very simple (Figure 9) to the highly complex (Figure 1). Figure 1, a 'rich' collage, includes 3D elements (two fabric butterflies taped to the collage), graphic images, images of people, collagedtogether pictures (that is, images that are pasted so as to overlap), pictures of clothing, pictures of animals, annotations in hand-written text, words cut out of printed material, and images of technology (such as mobile phones or cameras). This particular collage is so exuberantly decorated that the collage images spill over the boundaries of the paper backing.

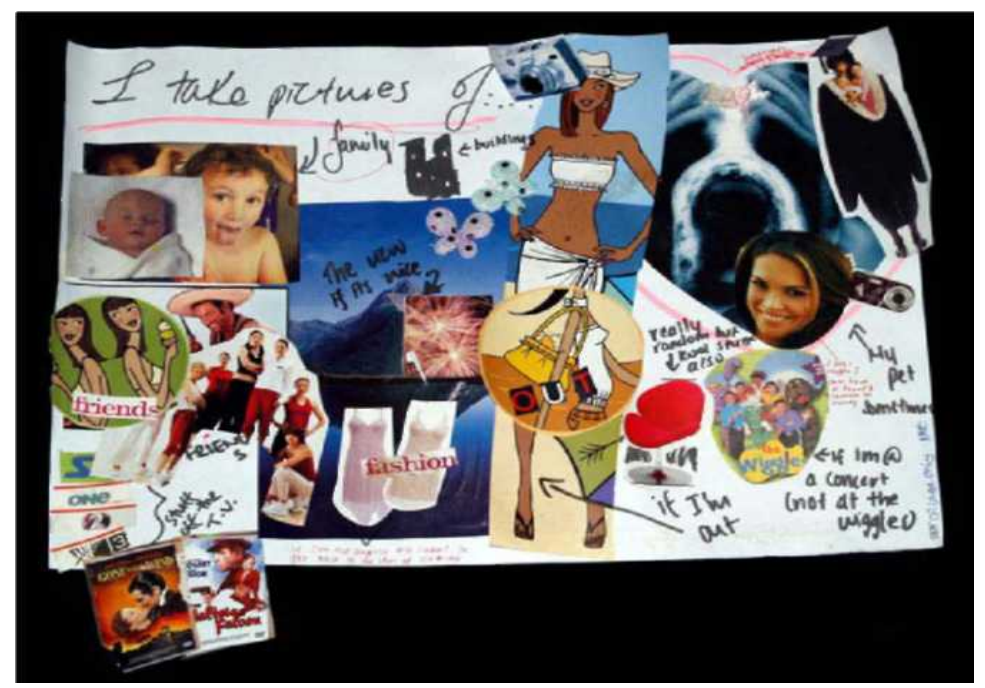

Figure 1: A rich collage

\begin{tabular}{|ll|}
\hline Function & Usability \\
Security & Financial concern \\
Safety & Feelings about phone \\
Privacy & Family \\
Contact & Friendship \\
Planning & No obvious theme \\
Location & \\
\hline
\end{tabular}

\section{Table 2: Thematic categories}

The thematic category most often seen was function: what the students would do with the phone or how they would use it (this is particularly common for collages exploring students' feelings about pxt facilities). Students were also generally sensitive privacy issues related to mobile use (notably that messages and phone numbers could be passed on to unintended recipients - see Figure 2); however, they also realised that their phones could afford them privacy, for example by allowing them to contact friends without being observed by other family members (see Figure 3). Mobiles could be useful in supporting closeness between friends and family members, but the students were keenly aware that phones could also be used to bully and humiliate (Figure 4). Also interesting was the participants' use of the phone to keep themselves physically secure; if anything goes wrong then it is relatively easy to get in touch with parents (see Figure 5). 


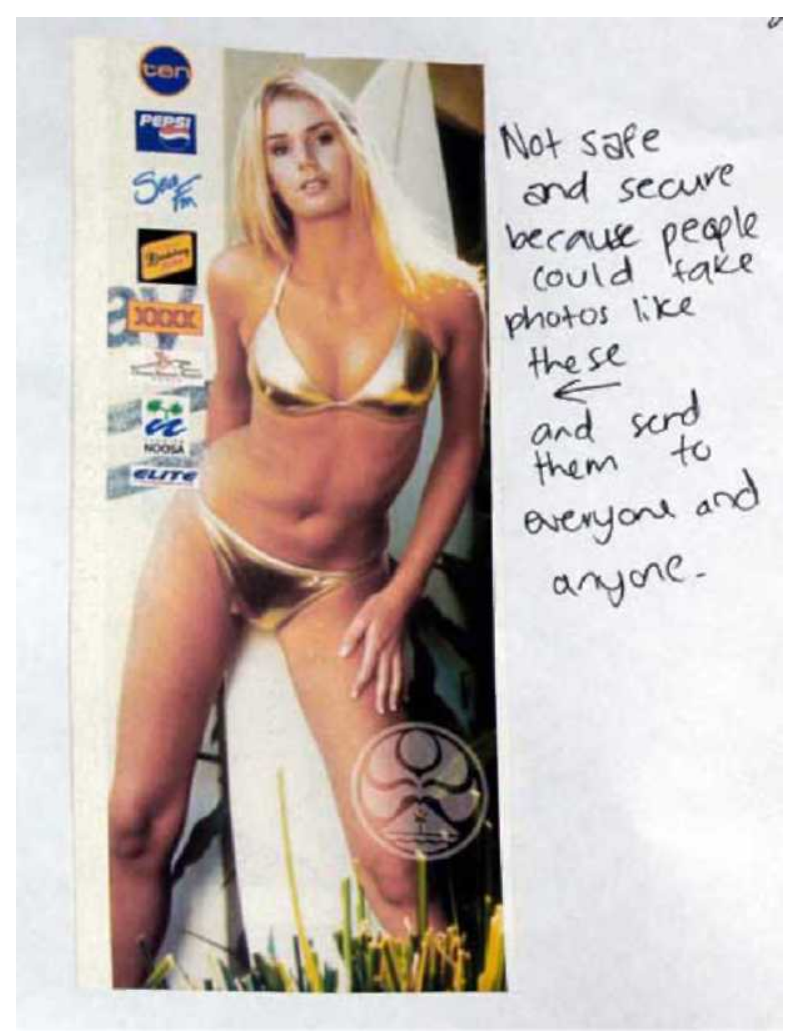

Figure 2: Privacy could be invaded by a pxt phone (text reads 'not safe and secure because people could take photos like these and send them to anyone' — while the student has identified it as a safety issue, it is also a privacy issue).

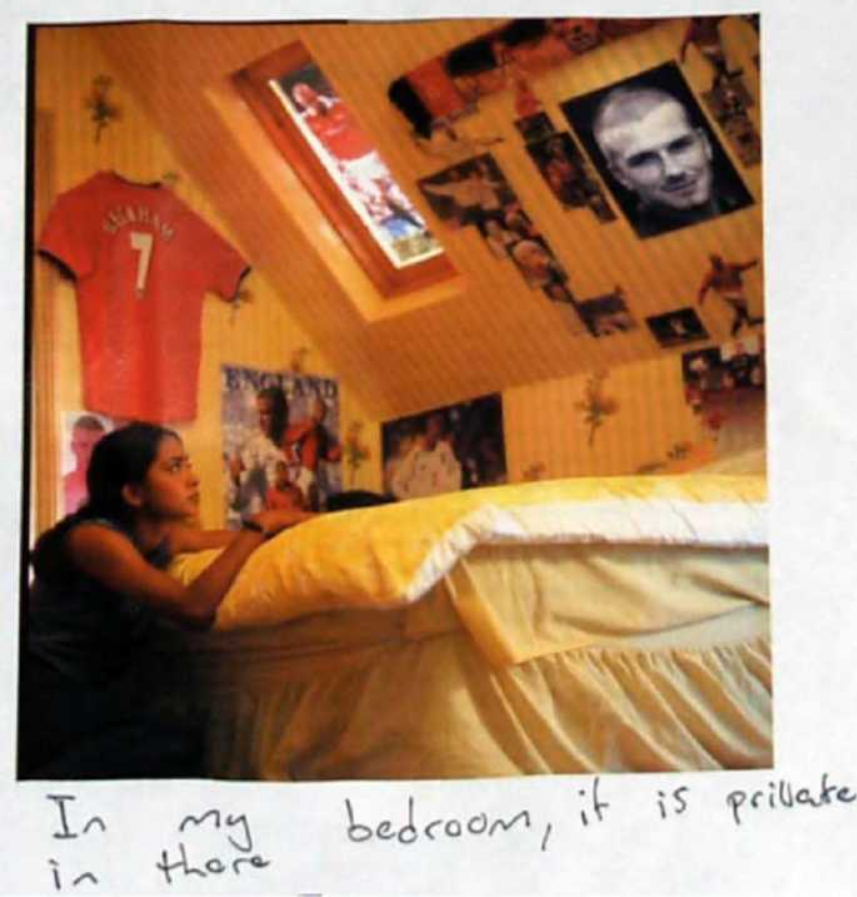

Figure 3: Privacy afforded by mobile phones. Text reads 'In my bedroom, it is private in there'.

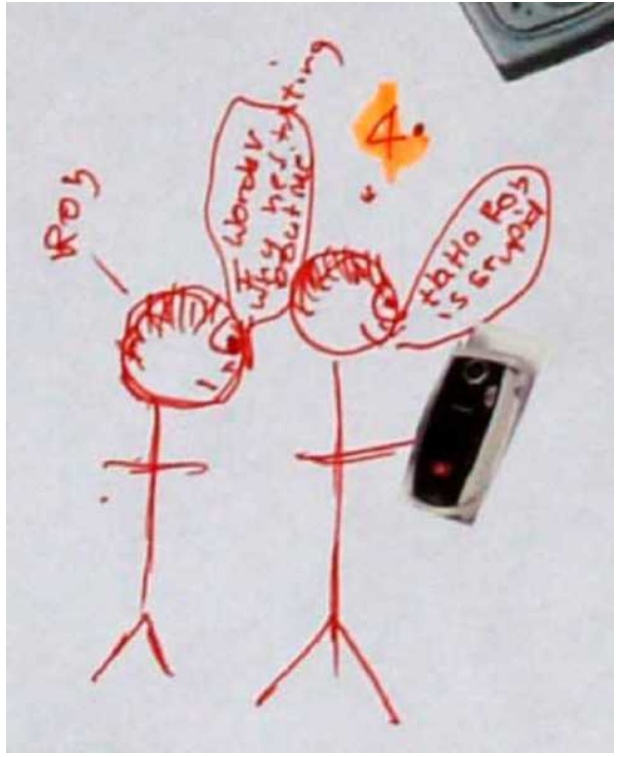

Figure 4: Cellphone cruelty between friends (Rob is saying, "I wonder why hes [sic] txting about me". Rob looks sad and worried. The other figure is is smiling as it says, "Haha Rob is stupid."

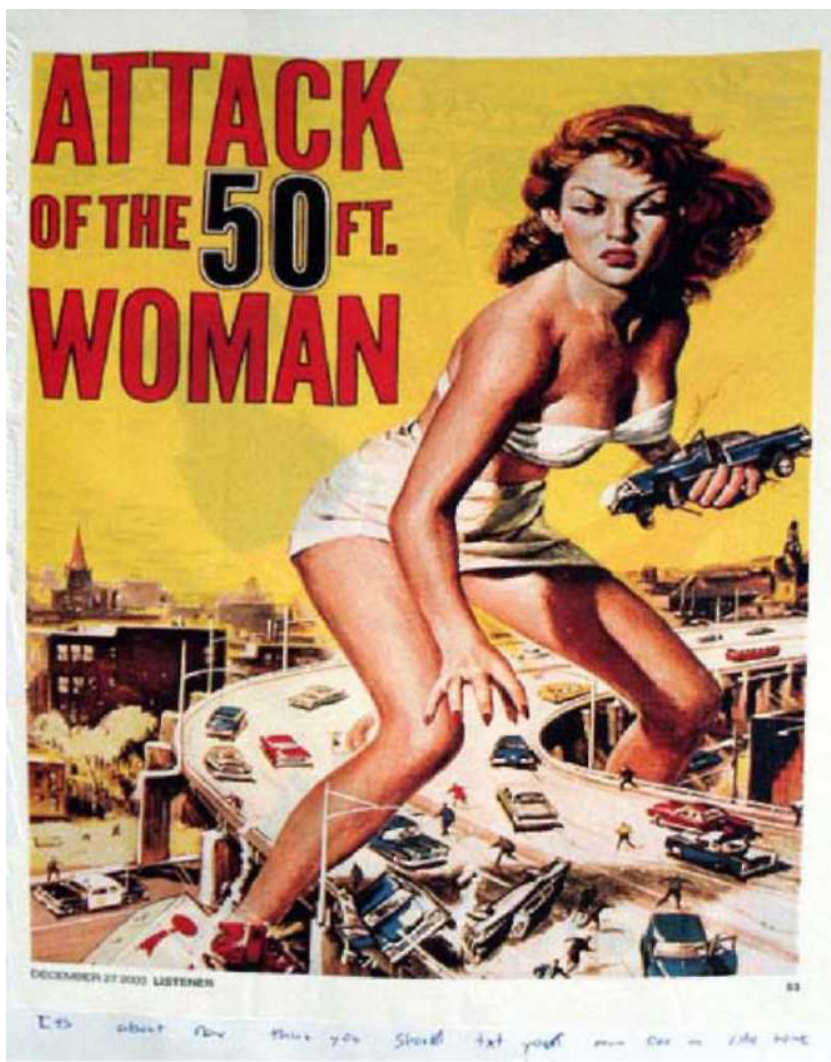

Figure 5: An example of phones being used for

security reasons (also an excellent example of humour). The text reads 'It's about now you should text your mum for a ride home' 
The results of this analysis showed a surprisingly rich body of work created by these students; there were many different types of content, and many different themes. Moreover most collages contained more than one type of content and more than one theme (see Figures 6 and 7).

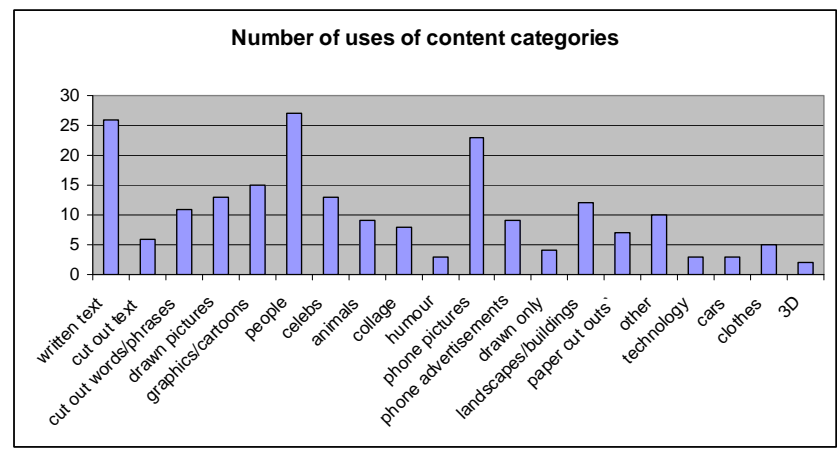

Figure 6: Number of uses of each content category

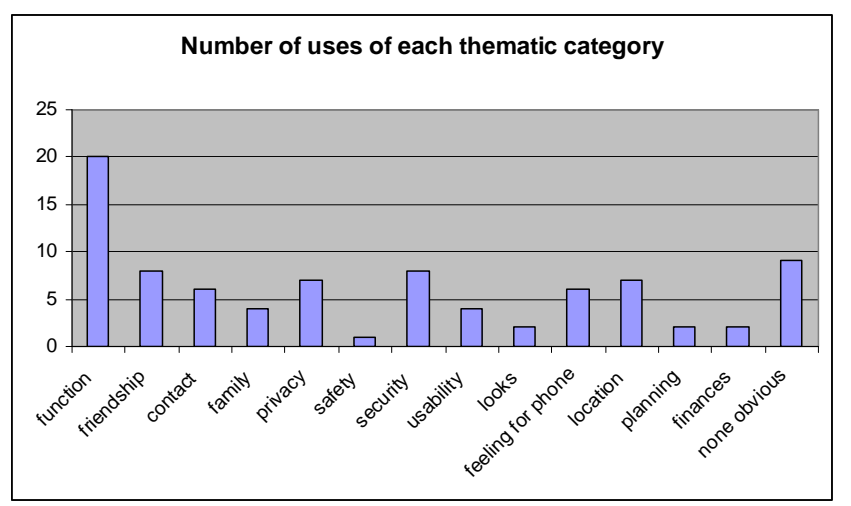

Figure 7: Number of uses of each thematic category

Of particular note is that of 39 collages, 29 yielded at least one obvious theme, and 21 yielded more than one obvious theme. Having so many themes available in collage makes it a rewarding data form to work with.

Collage is a relatively easy form of artifact to analyse and provides rich data when used with teenagers.

\section{DISCUSSION}

This experiment was performed under time constraints related to the students' school day; each school period is 50 minutes long, and we could only spend one period at a time with the students. While we were overseeing the experiments, many of the students complained about the lack of available time, and said that they felt their experience had been cut short.

In the debriefing questionnaire, students were asked to rate which of the three experimental conditions they were most confident with, which one they felt the most relaxed with, and which they thought would yield the most relevant data. The results of this questionnaire are in Table 3.

\begin{tabular}{|l|l|l|l|}
\hline & Collage & Focus group & $\begin{array}{l}\text { Collage- } \\
\text { then- } \\
\text { discussion }\end{array}$ \\
\hline $\begin{array}{l}\text { Most } \\
\text { confident }\end{array}$ & 7 & 4 & 1 \\
\hline Most relaxed & 8 & 1 & 3 \\
\hline Best data & 3 & 7 & 2 \\
\hline
\end{tabular}

Table 3: Student resnonses to the three conditions

Students were most confident and relaxed with the collage condition, though they thought the focus group would yield more information. They were least pleased with the collagethen-discussion condition, though this may have been a factor of time; 50 minutes is just barely long enough for collage and then discussion. The male students appeared less comfortable than the female students with the discussion and focus group; their body language was largely defensive, and they were not as quick to respond to questions regarding 'feelings' or other subjective matters.

The students did not have much experience with, or depth of insight into, pxt-capable phones. Few had access to a pxt phone, and most did not seem eager to possess one. While there was nearly always an obvious theme in these collages, it was almost invariably 'function', in the form of things the students would like to take pictures of if they had had a pxtcapable phone. Figure 8 shows a typical collage about pxting. Each image is hand-labeled with an explanation of the types of photos that the participant would like to take with a pxt-capable mobile ("cool animals", "friends" "sport," "good food", etc.). Given that collaging is a medium to explore emotions and experiences [12], it is not surprising that students struggled to create interesting collages of an activity that they'd had little exposure to, or interest in.

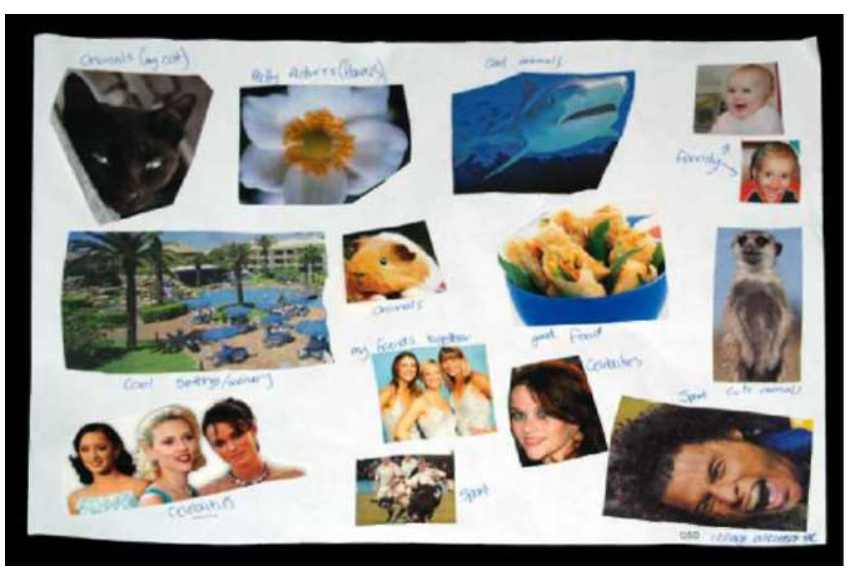

Figure 8: A collage about pxt-ing.

Collage is not for everyone. Some of the students, particularly the boys, appeared reluctant to collage. Perhaps it seemed a childish activity, or perhaps the open-ended and unconstrained nature of collage was initially threatening: we were, after all, working in a high schoolclassroom, where the students had come to expect a clear distinction to be made between 'right' and 'wrong' answers. Responses to this discomfort included opting to draw a picture instead 
(see Figure 9). Because some of the pictures drawn showed a deep level of insight (see Figure 11), if participants in this type of study are more comfortable drawing we would recommend encouraging that style of expression in future.

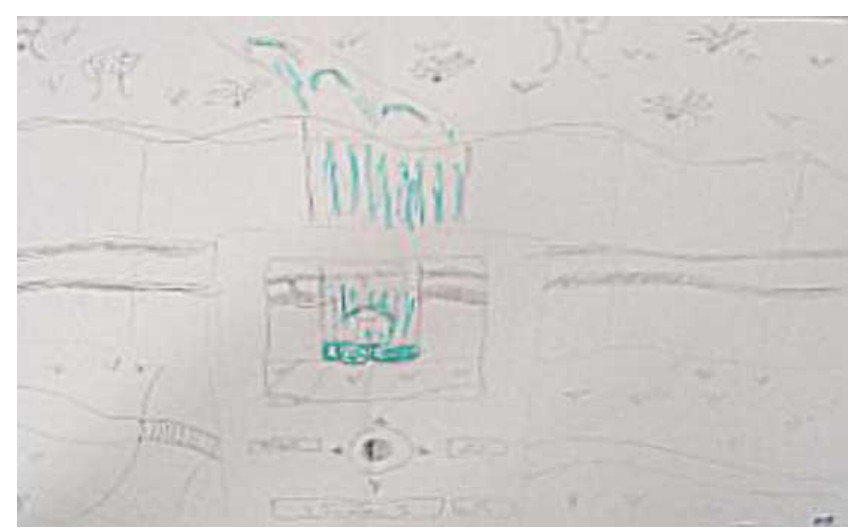

Figure 9: Drawing instead of collage

Some students were initially confused about the focus of each collaging task-again, mainly the boys, who were particularly puzzled by topics asking them to depict what they 'thought' or 'felt' about aspects of using their mobile phone. Several reacted by painstakingly cutting out pictures of mobile phones (see Figure 10), stripping the images of all context. This allowed them to feel that they were following instructions - they were, after all, including mobile phones in a collage-without challenging themselves.

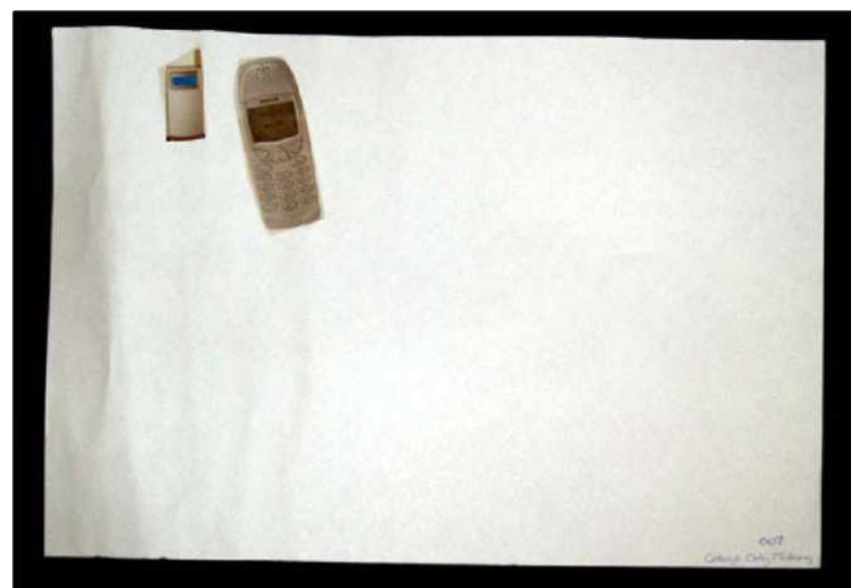

Figure 10: A complete collage by an uncertain participant

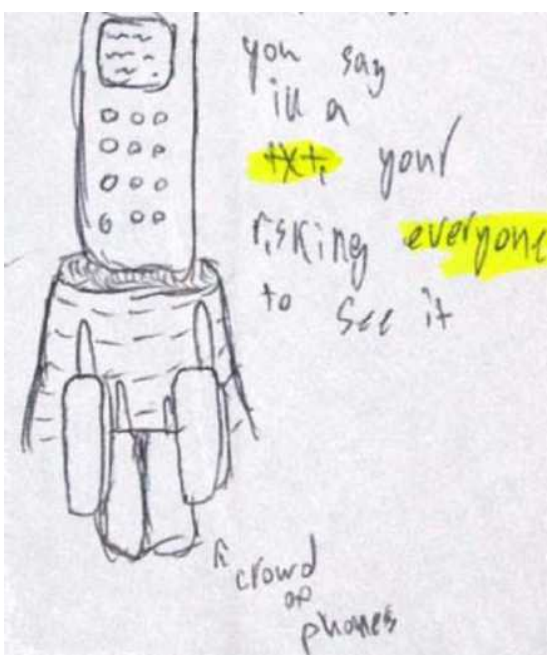

Figure 11: Insightful drawing (the main text reads 'whatever you say in a txt your [sic] risking everyone to see it').

During the experiment it became obvious that some students didn't understand the concept of collage as mixed media. One example is the young man who carefully drew a picture, and then glued a picture he found in a magazine over the top (Figure 12)—he thought that using an existing picture was more in accordance with the 'rules' of correct collage. Explaining what collage is, and perhaps having some examples of collage on hand may well warm participants up to this type of task and give them the confidence to express themselves more freely, with less concern for whether they are adhering to 'the rules'. Certainly we observed that once participants had completed one collage task they were more likely to settle down to the second one.

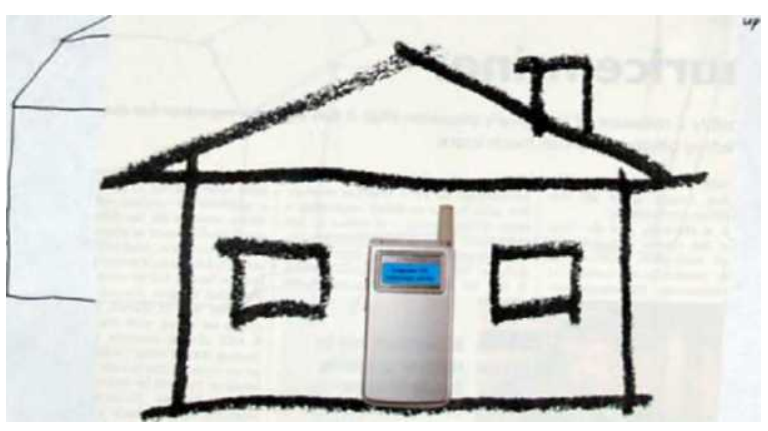

Figure 12: A magazine picture glued over a hand-drawn effort 


\section{CONCLUSION}

Collaging is a technique that is best used for eliciting experiences and impressions of systems or products that the participant has direct experience in using. If the participant is unfamiliar with the focus of the collage, or if the topic is not engaging or interesting, then the resulting collages will at best provide a pedestrian representation of superficial aspects of the topic. In this experiment, for example, the collages about pxt-ing mainly showed examples of pictures that a user could snap. By contrast, the collages of talking and texting on a mobile explored more subtle aspects of those behaviors.

While collage provides rich and easily analysed results, some time is needed to allow participants to collage to their satisfaction. Creating a collage takes more time than making a comment during a focus group session-the participant must decide on an idea to include in the collage, chose a representation for that idea (hand drawing, existing image, text), consider where to place it, and decide whether/how to annotate the representation. Part of the satisfaction of creating a collage lies in making it as attractive or striking as possible-and so rushing participants through collage construction may decrease their enjoyment of the experience, as well as reduce the insight and reflection that they put into their collage.

Earlier user studies incorporating collage differ in the degree to which the collage materials are constrained-[8], for example, provides participants with cutout pictures and words related to the topic of the study; [5] restricts the collages to participant-supplied digital photos; and Saunders [12] defines collage as "giving people a set of picture and word stickers and a space on which to arrange them according to your instructions". In our experiment, we gave participants stacks of popular magazines from which to select images, as well as drawing implements and assorted shaped items (such as plastic flowers and fabric butterflies). It seems likely that the greater the freedom of participants to choose their own collage materials (images and words), the greater their ability to convey more subtle and personal insights. This larger set of choices comes at a cost, however, of requiring more time to create the collage (since participants must now both select appropriate material and create the collage). Greater choice may also be more frustrating to some participants, as they search for the 'best' or most apt image.

\section{REFERENCES}

1. Battarbee, K., and Mattelmaki, T. (2002) Meaningful Product Relationships. In: Proceedings of the $3^{\text {rd }}$ Conference of Design and Emotion. Loughborough, UK. $\begin{array}{lllll}\text { Retrieved } & 7 & \text { April } & 2006 & \text { from }\end{array}$ http://smart.uiah.fi/kbattar/Meaningfulproductrelationshi ps.pdf

2. Bohm, D. (1998) On Creativity. Routledge, London.

3. Fallman, D. (2003) In Romance With The Tools Of Mobile Interaction: A Phenomenological Approach To The Design Of Mobile Information Technology. Larsson \& Co, Umea.

4. Gaver, W., Dunne, T., Pacenti, E. (1999) Cultural probes. ACM Interact 6:(1) pp.21-99

5. Hulkko, S., Mattelmaki, T., Virtanen, K., and Keinonen, T. (2004) Mobile Probes. In: Proceedings of NordiCHI'04, Tampere, Finland, 43-51.

6. Kellehear, A. (1993) The Unobtrusive Researcher: A Guide to Methods. Allen \& Unwin, St. Leonards, NSW.

7. Kerne, A. (2002) Concept-context-design: a creative novel for the development of interactivity. In:

Proceedings of the 4th conference on Creativity \& Cognition, Loughborough, UK, pp. 192-199.

8. Mattelmaki, T, and Battarbee, K (2002) Empathy Probes. In: Proceedings of the $7^{\text {th }}$ Biennial Participatory Design Conference, Malmo, Sweden, 266-271.

9. Moran, TP, Saund, E, van Melle, W, Gujar, AU, Fishkin, KP, and Harrison, BL (1999) Design and technology for Collaborage: Collaborative collages of information on physical walls. In: Proceedings of UIST '99, Asheville, North Carolina, 197-206.

10.Sanders, EB-N., Dandavae, U. (1999) Design for experiencing: New tools, in Overbeeke, C.J., Hekkert, P. (eds) Proceedings of the First International Conference on Design Emotion, TU Dlft.

11.Sanders, EB-N. (2001) Collective Creativity. Loop AIGA Journal of Interaction Design Education, no 3.

$\begin{array}{llll}\text { Retrieved } & 7 & \text { April } & 2006\end{array}$ http://loop1.aiga.org/content.cfm?Alias=sandersucd

12.Sanders, EB-N, and William, CT (2001) Harnessing People's Creativity: Ideation and Expression through Visual Communication. In: Focus Groups: Supporting Effective Product Development. Langford, $\mathrm{J}$ and McDonagh-Philip, D (Eds.). Taylor and Francis.

13.Sanders, EB-N. (2001) Virtuosos of the Experience Domain. In: Proceedings of the 2001 IDSA Education Conference. Retrieved 7 April 2007 from http://www.sonicrim.com/red/us/commune/papers/Sand ersIDSA2.pdf 